\title{
A coordenação civil-militar nas operações de paz e o Brasil: algumas considerações
}

\author{
Civil-military coordination in peacekeeping \\ operations and Brazil: some considerations
}

Rev. Bra. Est. Def. v. 3, nº 2, jul./dez. 2016, p. 25-39

\section{SÉRGIO LUIZ CRUZ AGUILAR}

\section{INTRODUÇÃO}

O presente artigo foi preparado a partir da apresentação do autor na mesa redonda 'A Participação Brasileira em Operações de Paz e seus Reflexos para as Relações Civis-Militares no País', durante o IX Encontro Nacional da Associação Brasileira de Estudos de Defesa e, por conta disso, mantém o tom coloquial em algumas partes. O texto parte das relações civis-militares de maneira mais ampla para apresentar algumas considerações sobre o tema nas operações de paz, especialmente a necessidade de coordenação entre os diversos componentes civis, militar e policial. Encerrando, aborda o papel dos militares brasileiros integrantes de operações de paz nesse âmbito, com ênfase em algumas características do militar brasileiro que contribuem para as relações entre os civis e os militares dentro das operações de paz.

\section{RELAÇÕES CIVIS-MILITARES}

A questão das relações civis-militares se deu no âmbito da Ciência Política e das Relações Internacionais em um debate relacionado, principalmente, com o controle civil sobre as Forças Armadas. No período da 'redemocratização’ dos países sul-americanos, foi considerável a produção acadêmica nesse sentido, especialmente em países como o Chile e a Argentina, com vários projetos desenvolvidos com financiamento de agências externas. ${ }^{1}$ A produção acadêmica nesses países foi maior no Brasil, até mesmo

Sérgio Luiz Cruz Aguilar - Livre Docente em Segurança Internacional (UNESP). Doutor em História (UNESP). Pós-doutor pela Universidade de Oxford (Reino Unido). Professor da UNESP Campus de Marília/SP. Coordenador do Grupo de Estudos e Pesquisa sobre Conflitos Internacionais (GEPCI) e do Observatório de Conflitos Internacionais (OCI). E-mail: sergioaguilar@marilia.unesp.br 
por conta de os regimes militares terem sido em vários pontos diferentes e, subsequentemente, o mesmo ocorreu com os processos de transição para os governos civis. $\mathrm{O}$ foco dos estudos sobre as relações civis-militares foi direcionado então, e de maneira lógica, para assegurar a subordinação do soldado ao Estado e, no bojo desses trabalhos ocorreu toda uma análise dos processos de transição de regimes autoritários para regimes democráticos.

O mesmo ocorreu nos países do Leste Europeu ao final da Guerra Fria e da União Soviética com o envolvimento da Europa Ocidental nos esforços de 'construção' de novos Estados, governos e sociedades democráticas naquela parte do continente. ${ }^{2}$

Outro campo onde ocorreram discussões sobre as relações civis-militares, ligadas tanto às situações e regiões apresentadas acima quanto às operações de paz, foi o dos processos de reforma do setor de segurança (RSS). O conceito, originário do discurso proferido pela Secretária de Estado para o Desenvolvimento Internacional do Reino Unido, Clare Short, em 1999, acabou se tornando "um pilar central das doutrinas de construção da paz (peace-building) e construção do Estado (state-building)" e representou "um ponto de convergência entre os campos do desenvolvimento, segurança e da governança - uma manifestação do nexo segurança-desenvolvimento que caracterizou as políticas de construção da paz e construção do Estado na última década” (Sedra 2014, 130).

Os processos de RSS têm sido executados em transições do autoritarismo, da fragilidade, da pobreza e, principalmente, dos conflitos armados. Hänggi (2004) apontou três abordagens para a reforma do setor de segurança: como um instrumento para melhorar a eficiência e a eficácia da assistência ao desenvolvimento; como ferramenta para facilitar a coordenação prática e integração conceitual das reformas do aparato de segurança interna e de defesa em Estados que haviam saído de períodos autoritários; e no contexto da reconstrução nos Estados que emergiram de conflitos violentos intraestatais ou interestatais.

Nesses processos de reforma, as relações civis-militares se dão tanto em relação aos governos civis e suas forças armadas como em relação aos doadores e agências internacionais com as forças armadas e policiais locais que devem ser 'reformadas'. O alargamento do conceito de setor de segurança na década passada, passando a incluir forças de defesa e de aplicação da lei, sistema correcional, serviços de inteligência, setor judiciário e instituições do Estado que desempenham papéis na gestão, supervisão, elaboração e implementação da segurança, levou à ampliação das relações estabelecidas entre os diversos atores do setor, incluindo organizações civis que exercem um papel importante na fiscalização do setor (Aguilar 2014a). 


\section{AS RELAÇÕES CIVIS-MILITARES NAS OPERAÇÕES DE PAZ}

No âmbito das operações de paz, a análise se dá em torno das interações diversificadas, transversais e verticais, que caracterizam as relações entre civis e militares presentes no mesmo ambiente das operação de paz, entre tropas, policiais e os diversos componentes civis que fazem parte das atuais missões caracterizadas pela 'multidimensionalidade' e pelo planejamento e execução de forma integrada. ${ }^{3}$

As operações de paz tradicionais desdobradas em conflitos envolvendo Estados e suas forças armadas tinham basicamente a função de buscar o cessar-fogo, tréguas e armistícios, o patrulhamento de fronteiras e zonas de exclusão militar, o apoio à retirada de tropas e o acompanhamento de negociações para a assinatura de tratados de paz. Dessa forma, envolviam os membros das operações, a maioria militares, e os governos envolvidos. Com a ampliação dos mandatos que passaram a ser orientados para a ajuda humanitária, verificação da situação dos direitos humanos, policiamento, supervisão de eleições e auxílio a governos em diversos setores, dentre outras atividades, a quantidade de atores presentes no ambiente de uma operação de paz também cresceu.

Além dos componentes civis, policial e militar de uma operação, inúmeras Organizações Não Governamentais (ONGs), Organizações Internacionais (OIs), agências, programas e fundos das Nações Unidas, representações de Estados, agências de desenvolvimento, dentre outros, se fazem presentes no terreno, tornando o ambiente mais complexo, com a consequente necessidade de coordenação. Isso porque, diferente da estrutura hierarquizada da missão de paz, e das relações de subordinação entre seus membros, do nível político ao tático, os demais atores atuam de forma independente e somente a coordenação permite o melhor aproveitamento das diversas capacidades e maior eficácia de suas ações.

Nesse âmbito, o bom relacionamento do componente militar com civis, quer sejam das diversas seções da operação de paz, quer sejam os que não fazem parte da estrutura dessas operações, avulta de importância. As relações entre o contingente militar brasileiro com a Embaixada do Brasil em Porto Príncipe foram fundamentais para as ações de assistência humanitária após o terremoto que assolou o Haiti em 2010. As relações do contingente militar brasileiro da UNTAET e da UNMISET com a Embaixada do Brasil em Dili foram importantes para a realização de projetos brasileiros de cooperação desenvolvidos no Timor Leste. ${ }^{4}$

O caso do terremoto no Haiti é um dos maiores exemplos da necessidade de boas relações e coordenação entre militares e civis em situações complexas. Com a destruição física e centenas de milhares de mortos, feri- 
dos e desaparecidos, além da missão da ONU presente no país - Missão das Nações Unidas para a Estabilização no Haiti (MINUSTAH), em poucos dias o governo dos Estados Unidos (EUA) enviou a Força Tarefa Conjunta Haiti - Joint Task Force - Haiti (JTF-H) com cerca de 22 mil militares, com meios aéreos e navais para auxiliar nos esforços de ajuda. Ao mesmo tempo, mais de 100 países enviaram equipes de busca e resgate e de saúde, além de uma grande quantidade de ajuda como água, alimentos, remédios, itens de abrigo, dentre outros. Além disso, inúmeras ONGs deslocaram suas equipes, juntando-se às mais de mil organizações que já operavam no Haiti. A grande quantidade de atores envolvidos nas ações que se seguiram ao terremoto, por vezes conflitantes, demandaram um enorme esforço de coordenação (Aguilar 2014b).

O primeiro problema no âmbito da coordenação e das relações civis-militares de maneira mais ampla se relaciona com culturas organizacionais. As organizações, instituições e agências têm culturas próprias, normas e procedimentos operacionais específicos e interesses próprios, e algumas são avessas a se coordenarem com o comando da operação. Por mais estranho que possa parecer, a ONU tem dificuldade de coordenar atividades das operações de paz com suas próprias agências, fundos e programas.

Com a ampliação do escopo das operações de paz e o número cada vez maior de atores, a presença deles num mesmo ambiente gera uma série de tensões como: sobreposição de papéis, diferentes atores disputando ou exercendo a responsabilidade por uma mesma atividade; duplificação de esforços, instituições diferentes realizando atividades numa mesma área; esforços em sentidos contrários, instituições conduzindo projetos numa determinada direção enquando outra conduz em direção oposta; falta de conhecimento de atividades dos diversos componentes e dos membros desses componentes em relação às demais instituições, dentre outras. Essas tensões normalmente resultam em dispêndio de recursos, ineficácia e ineficiência das ações e, principalmente, dificuldade para os 'locais' definirem interlocutores e objetivos de projetos propostos e/ou implementados em seus países.

Dentre as tensões, talvez a que mais se faz presente em um ambiente de operação de paz entre civis e militares seja o fato de que esses tendem a pensar em curto prazo enquanto os primeiros pensam mais em médio e longo prazo. Enquanto os militares forçam para que os projetos e programas foquem nas causas próximas do conflito e, com isso, na resolução rápida dos problemas de segurança, os civis se esforçam na priorização de projetos de longo prazo, visando as causas mais profundas do conflito, normalmente ligadas às questões de desenvolvimento e governança. 
Outro problema são as disputas entre organizações, instituições e agências, e no interior delas, tema analisado por autores que estudaram instituições e seus processos decisórios (mesmo que em situações específicas), incluindo a burocracia estatal. ${ }^{5} \mathrm{~A}$ mesma disputa que acontece entre instituições do Estado ocorre dentro das Nações Unidas, entre os diversos componentes e seções dentro de uma operação de paz, e entre os integrantes dessas operações com os demais atores presentes no mesmo ambiente, seja pela busca por recursos, seja por notoriedade, isto é, por levar o crédito de ter 'resolvido' o conflito ou parte importante dele, dentre outras.

Uma das formas encontradas pela ONU para diminuir o problema das relações civis-militares e melhorar a coordenação de seus componentes e deles com os demais atores presentes no ambiente de uma operação de paz foi mudar o quadro organizacional das missões.

A mudança está ligada ao duplo sentido das relações e coordenação civil-militar. Uma é a coordenação entre os contingentes militares e os parceiros civis, incluindo os componentes civis da operação de paz, agências, fundos e programas da ONU, componente policial, governo do Estado hospedeiro, ONGs e organizações comunitárias ou de bases populares. Outra é a função de coordenação humanitária civil-militar que permite a interface entre os atores militares e humanitários.

A política da ONU para a coordenação civil-militar nas missões de paz integradas (UN-CIMIC) diz que ela é

uma função militar de estado-maior, em uma missão integrada da ONU. Facilita a interface entre os componentes civil e militar da missão, bem como policiais, organizações humanitárias e instituições de desenvolvimento para atingirem os objetivos da missão (UN, DPKO/ DFS 2010, 2, tradução nossa).

O Escritório de Coordenação para Assuntos Humanitários (Office of Coordination for Humanitarian Affairs - OCHA) conceituou a Coordenação Civil-Militar (UN- CIMIC) como sendo

Diálogo essencial e interação entre civis e militares em emergências humanitárias quando se faz necessário proteger e promover os princípios humanitários, evitando competição, minimizando inconsistências, e quando apropriado, identificando objetivos comuns. As estratégias básicas vão da coexistência à cooperação. A coordenação é uma responsabilidade partilhada, facilitada pela ligação e formação comum (UN 2008, 11, tradução nossa, ênfase no original).

Na sede da ONU, em 1992, foi criado o Departamento de Assuntos Humanitários (Department of Humanitarian Affairs - DHA), substituído 
em 1998 pelo OCHA, responsável por gerenciar as atividades de assistência humanitária, que estabalece escritórios nas diversas operações de paz.

As operações tradicionais, e mesmo as que já poderiam ser consideradas multidimensionais, na década de 1990, tinham o Representante Especial do Secretário Geral - Special Representative of the Secretary-General (SRSG) como chefe, secundado pelo Vice Representante Especial, normalmente um funcionário de carreira da ONU com bastante experiência, que normalmente era o Chefe da Administração. Com o conceito de missões de campo integradas, o chefe da missão (SRSG), passou a ter sob sua subordinação os componentes da missão e o UN Country Team (UNCT), responsável por coordenar as diversas agências, fundos e programas das Nações Unidas presentes na área da operação. Além disso, foram criadas as funções de: Coordenador Residente - Resident Coordinator (RC), responsável por coordenar as atividades de desenvolvimento da ONU em nível de país, de conformidade com os objetivos e prioridades do governo e dos mandados e objetivos das organizações do sistema da Organização; e a Equipe Humanitária do País - Humanitarian Country Team (HCT), com um Coordenador Humanitário - Humanitarian Coordinator (HC), formada por representantes das agências da ONU e ONGs, contando com representantes da Cruz Vermelha Internacional como observadores, para coordenar as atividades das organizações humanitárias (Aguilar 2014b).

As missões multidimensionais atuais, incluindo a MINUSTAH no Haiti, passaram a operar com o SRSG e dois vices: um voltado para dentro da missão, e um voltado para fora da missão, o Deputy Special Representative of the Secretary-General (DSRSG) que, normalmente, é também o coordenador residente (RC) e o coordenador humanitário (HC) e responsável pela interface com os diversos atores humanitários e de desenvolvimento.

Enquanto a ligação entre os diversos componentes da operação de paz é funcional e coordenada por um dos vices (DSRSG), a ligação com os demais atores, incluindo a 'coordenação humanitária', se dá de maneira praticamente informal sob responsabilidade do outro vice (DSRSG/RC/HC). Nesse sentido, o OCHA procura trazer os demais atores para participar de um sistema de coordenação baseado em clusters (grupos/agrupamentos em áreas específicas). Cada cluster é chefiado por uma organização ou agência com maior aptidão para determinada área e reúne representantes das diversas instituições, organizações (internacionais e não governamentais) e agências, locais e internacionais, envolvidas com aquela atividade. Os clusters contam representantes dos componentes policial e militar, uma vez que os meios desses componentes são utilizados seja para garantir segurança das atividades, seja provendo meios logísticos para apoiá-las. Por exemplo, o cluster saúde normalmente é chefiado pela Organização Mundial de Saúde 
(OMS), já o de refugiados e de desalojados normalmente é chefiado pelo Alto Comissariado da ONU para Refugiados (ACNUR) ou a Organização Internacional de Migrações (OIM).

No Haiti, em 2012, o Escritório de Coordenação de Assistência Humanitária em Porto Príncipe tinha cadastradas 1.300 ONGs que participavam do sistema de clusters. Na realidade, o número de ONGs operando no país era bem maior e essas 1.300 foram as que atenderam ao chamado da ONU e se propuseram a participar do sistema de coordenação (Aguilar 2014b, 128). Também é interessante salientar que a necessidade de coordenação cresceu em decorrência do terremoto naquele país e levou várias ONGs, programas, fundos e agências a buscarem a coordenação para poderem prestar a ajuda humanitária. Ou seja, a coordenação entre os diversos atores, onde também se inserem relações civis-militares, é complexa, informal e depende da propensão da maior parte deles em participar.

A coordenação civil-militar que se dá dentro do ambiente da operação de paz, por subordinação, dentro da hierarquia entre os diversos componentes da operação, resultou na criação de seções que não faziam parte do organograma das missões 'tradicionais'. Os componentes militares têm agora a Seção de Assuntos Civis (U9) e as unidades nível batalhão têm suas Seções de Assuntos Civis (G9), que se ligam de alguma forma, e dentro de suas áreas de operação, com policiais e os civis da própria missão de paz, do Estado hospedeiro (host country) ou das diversas agências, instituições e organizações internacionais que nele operam.

As Seções de Assuntos Civis do componente militar (U9, G9) têm que estabelecer relações com civis da ONU, por exemplo uma estreita ligação com a Seção de Assuntos Civis, bem como com civis locais, por exemplo, com líderes comunitários para a idealização de Projetos de Impacto Rápido (Quick Impact Projects) e com parceiros nacionais para a execução desses projetos. A Seção de Assuntos Civis do Batalhão Brasileiro (BRABAT) da MINUSTAH tinha 276 instituições civis relacionadas, sendo que 53 se encontravam dentro da área de operações e constavam como prioridade para os trabalhos da Seção. ${ }^{6}$ Como exemplo das relações entre militares brasileiros em missões de paz e civis externos e locais, em junho de 2010 o BRABAT 2 realizou junto com a ONG brasileira Viva Rio estágio de líderes de grupos de autodefesa contra desastres naturais, repassando conhecimento e técnicas com a finalidade de preparar grupos para agirem em caso de desastres. ${ }^{7}$

As relações entre os militares e as comunidades locais, incluindo líderes políticos, religiosos e comunitários, apresentam dois aspectos importantes: a observação e compreensão das diferenças culturais, utilizando essa compreensão para ajudar a consecução de objetivos da operação; e a iden- 
tificação das necessidades dessas comunidades onde os militares atuam. Isso no sentido de criar um ambiente propício para a atuação externa e de empoderar a população local, criando condições para que ela assuma, gradualmente, as tarefas realizadas pelos militares. Esses aspectos ficam bem claros na atuação das unidades militares de engenharia da operação de paz que atuam em apoio à missão executando atividades de assistência civil às comunidades e de apoio à infraestrutura, por exemplo, trabalhos técnicos de engenharia, terraplanagem, tratamento de água e obras em geral. A execução dessas atividades envolvem uma relação muito próxima entre civis e militares e devem ser paulatinamente transferidas para as instituições civis locais, conforme suas capacidades vão sendo 'construídas' ou 'melhoradas' pela operação de paz.

\section{O BRASIL E AS RELAÇÕES CIVIS-MILITARES NAS OPERAÇÕES DE PAZ}

A questão das relações entre militares brasileiros e civis presentes no ambiente das operações de paz está muito ligada às relações entre os militares e civis no Brasil. Diferente de outros países, as Forças Armadas no Brasil sempre tiveram uma relação muito estreita com a sociedade, independente dos diversos períodos de nossa história. As relações aumentaram com a chamada 'redemocratização' ocorrida após o período dos governos militares por conta das chamadas ações subsidiárias ou ações cívico-sociais (ACISO) realizadas pelos militares e voltadas exclusivamente para as comunidades.

As atividades de distribuição de água e alimentos no sertão nordestino que tradicionalmente são realizadas pelas Forças Armadas, especialmente o Exército Brasileiro, implicam em relações diretas com as comunidades e em relações de coordenação com autoridades civis em diversos níveis local (prefeituras), estadual (governos dos estados) e nacional como, por exemplo com a Companhia Nacional de Abastecimento (CONAB), no caso de alimentos.

As atividades de assistência às comunidades da Marinha do Brasil em áreas remotas da Amazônia, onde avulta de importância o atendimento médico que é prestado por navios itinerantes naquela região, implica em relações de coordenação desde o nível político até o tático, de execução da missão.

A mobilidade de militares pelo território nacional durante a carreira auxilia no conhecimento e compreensão das diversidades culturais existentes no país, e como conviver com elas, o que facilita a adaptação dos militares em ambientes culturais diferentes quando enviados para missões de paz. Consequentemente, a tradição de relacionamento com a sociedade 
civil, compreendendo suas diversidades, facilita as relações entre o militar brasileiro e os civis locais e de outras partes do mundo presentes nessas missões.

A maior parte das operações atuais se dá em relação à violência interna. Nesse sentido, quando os mandatos determinam, o componente militar tem que usar a força para estabelecer uma situação mínima de segurança para que as demais atividades, especialmente as de 'construção da paz', possam ser realizadas. No entanto, ao mesmo tempo em que existem grupos geradores de violência que devem ser combatidos, há a presença da população civil que deve ser protegida. Componentes militares de alguns países têm dificuldade em atuar nesse tipo de ambiente, ou seja, de fazer a transição do preparo para atuar numa situação de guerra entre forças armadas para a de atuar numa situação de operação de paz.

Os militares brasileiros, em geral, sentem menos dificuldade nesse âmbito por conta de seu envolvimento em ações dentro do território nacional no bojo das chamadas operações de Garantia da Lei e da Ordem. As Forças Armadas, especialmente o Exército, têm atuado nas favelas do Rio de Janeiro em apoio ao combate ao tráfico de drogas. A primeira 'Operação Rio’ data de meados da década de 1990. Um dos princípios básicos dessas operações é que os civis não são inimigos. As ações devem ser realizadas garantindo a segurança das comunidades, que devem ser tratadas com respeito. Nessas ações, além das relações operacionais com policiais, os militares têm que estabelecer relações com civis de órgãos estaduais, líderes comunitários e ONGs que atuam nessas comunidades. Dessa forma, há menos tensões com a transposição dessas ações internas para o ambiente das operações de paz do que normalmente ocorreriam.

Os primeiros contingentes militares brasileiros no Haiti combateram gangues armadas nas favelas da capital Porto Príncipe, usando a força como autorizado pelo mandato do Conselho de Segurança, mas procurando não só manter as comunidades em segurança, como ganhar a confiança delas e, com isso, garantir seu apoio e obter informações necessárias para o planejamento e execução das operações.

Anos atrás, o atendimento a um pedido para pesquisar sobre uma possível 'maneira brasileira de executar operações de paz' resultou num texto chamado "Uma cultura brasileira de missões de paz” (Aguilar 2012). Não há uma maneira própria brasileira, no entanto, algumas características do povo e do militar brasileiro auxiliam o desenrolar das atividades envolvidas numa operação de paz, principalmente o relacionamento com os demais integrantes e atores presentes no mesmo espaço operacional.

Em relação às relações civis-militares, por conta dos diversos exemplos obtidos por meio de entrevistas sobre a participação brasileira com tropas 
em Moçambique, Angola, Timor Leste e no Haiti, dois pontos ficaram bem claros. Primeiro, o processo de seleção e de preparação desenvolvido no Brasil, seguindo os modelos enviados pela ONU que incluem o tema. $\mathrm{O}$ Centro Conjunto de Operações de Paz do Brasil (CCOPAB), por exemplo, ministra curso Coordenação Civil-Militar das Nações Unidas (UN-CIMIC) para os militares indicados para participar de operações de paz. Segundo, o espírito de cumprimento da missão, no jargão popular “vestir a camisa”, ou seja, se imbuir que naquela determinada situação e período, o militar está a serviço das Nações Unidas e deve se empenhar para ajudar a Organização no bom cumprimento de suas atividades. Dessa forma, a boa preparação e o sentimento de bem cumprir a missão levam os militares a compreenderem que boas relações e coordenação com os diversos civis presentes no espaço da operação de paz são necessárias, se esforçando para que elas ocorram da melhor maneira possível.

\section{CONCLUSÕES}

Em termos de relações e, principalmente, coordenação civil-militar no âmbito das operações de paz houve uma evolução muito grande nas duas últimas décadas. Da completa inexistência de normas e estruturas nesse sentido até início da década de 1990, uma série de documentos foram produzidos e órgãos específicos foram criados na ONU e nas operações de paz.

As operações da ONU na antiga Iugoslávia chegaram a ter um efetivo de mais de 52.000 peacekeepers em agosto de 1995, mas não havia qualquer órgão nas suas estruturas para lidar com o tema (Aguilar 2003, 130). Inúmeras ONGs operavam no mesmo espaço das operações 'sem se conversar', o que acontecia apenas em situações específicas e em caso de necessidade de uma das partes, normalmente relacionadas com segurança. Hoje se associa a necessidade de coordenação por conta da multidimensionalidade e robustez das operações. No entanto, a maior operação de paz em andamento atualmente, a United Nations Organization Stabilization Mission in the Democratic Republic of the Congo (MONUSCO) opera com um efetivo de 22.590 pessoas, ou seja, menos da metade do efetivo que se fazia presente nas antiga Iugoslávia (UN 2016).

Logo, pode-se inferir que a questão central não era a robustez das operações mas uma deficiência normativa, estrutural e de procedimentos que não indicavam a necessidade, nem incentivavam a coordenação civil-militar. Como a ONU aprendia (e ainda aprende) com acertos e erros, essas deficiências ficaram mais claras nos casos em que a Organização falhou em cumprir com seus objetivos, como por exemplo na Somália, Ruanda e na antiga Iugoslávia, todas na primeira metade da década de 1990, e foram 
apresentadas pelos diversos relatórios das Nações Unidas, incluindo o famoso Relatório Brahimi, ${ }^{8}$ que resultaram em profundas mudanças na maneira de executar operações de paz, com reflexos positivos para a evolução das relações civis-militares nessas operações.

Hoje, uma política de coordenação civil-militar, bem como uma série de diretrizes e instruções sobre a coordenação civil-militar estão em vigor. O tema faz parte dos módulos de treinamento divulgados pela ONU para serem aplicados na preparação dos peacekeepers. Uma série de órgãos e células de coordenação operam no âmbito das operações integradas. Fora das Nações Unidas, uma quantidade considerável de ONGs que atuam junto com as missões de paz procuram participar dos diversos clusters de coordenação, ou seja, há mais atores militares e civis (de segurança, humanitários ou de desenvolvimento) se relacionando e coordenando suas atividades do que anos atrás. Pode-se dizer que mesmo que cada um deles tenha objetivos próprios dentro do ambiente de uma operação de paz, há maior propensão para a coordenação civil-militar

Os militares brasileiros têm sido preparados para se relacionarem da melhor maneira possível com os civis presentes nas áreas operacionais, e de acordo com o preconizado pelas Nações Unidas para as operações de paz. Sem dúvida, suas posturas nesse âmbito tem relação com as relações civis-militares que são desenvolvidas no Brasil. Por outro lado, os ensinamentos colhidos nas relações estabelecidas nas operações de paz, seja por militares em missões individuais, seja integrando contingentes armados, são utilizados para aperfeiçoar as relações com civis no Brasil, especialmente nas operações de Garantia da Lei e da Ordem.

\section{REFERÊNCIAS}

Aguilar, S. L. C. 2003. A Guerra da Iugoslávia: uma década de crises nos Bálcãs. São Paulo: Usina do Livro.

. 2012. Uma cultura brasileira de missões de paz. In: Brigagão, C., Fernandes, F. (Org.). Diplomacia Brasileira para a Paz. Brasília: FUNAG.

2014a. Reforma do Setor de Segurança: visão geral e proposta de planejamento. In: Aguilar, S. L. C. (Ed.). Reforma do Setor de Segurança: teoria, prática e crítica. São Paulo, Porto de Idéias.

Idéias.

2014b. Gerenciamento de Crises: o terremoto no Haiti. São Paulo: Porto de 
Allison, G. T. 1971. Essence of Decision: explaning the Cuban Missile Crisis. Boston: Little Brown.

Brabat. 2010. Entidades Cadastradas - BRABATT 1/12. Porto Príncipe, 20 Dez. 2010 , mimeo.

Cremona, M. 2003. State Aid Control: Substance and Procedure in the Europe Agreements and the Stabilisation and Association Agreements. European Law Journal, 9 (3), 265-287.

EU. 1999. Council Regulation (EC, Euratom) n. 99/2000 of 29 December 1999 concerning the provision of assistance to the partner states in Eastern Europe and Central Asia. Tacis programme (2000-2006). Disponível em: <http://eur-lex.europa.eu/legal-content/EN/ TXT/HTML/?uri=URISERV:r $17003 \&$ from=EN $>$. Acesso em: 22 dez. 2016.

1989. Council Regulation (EEC) n. 3906/89 of 18 December 1989 on economic aid to the Republic of Hungary and the Polish People's Republic. Disponível em: <http://eur-lex.europa.eu/legal-content/EN/ TXT/?uri=URISERV\%3Ae50004>. Acesso em: 22 Dez. 2016.

Feaver, P. 1998. Crisis as Shirking: An Agency Theory Explanation of the Souring of American Civil-Military Relations. Armed Forces and Society, 24 (3), 407-434.

Hänggi, H. 2004. Conceptualising Security Sector Reform and Reconstruction. In: Hänggi, H. (Ed). Reform and Reconstruction of the Security Sector. Münster: LIT Verlag.

López, E. (Ed.). 2007. Control civil sobre los militares y política de defensa en Argentina, Brasil, Chile y Uruguay. Editorial Altamira: Argentina.

1995. Defensa No Provocativa y Relaciones Cívico-Militares: Reflexiones sobre el Caso Argentino. In: Cáceres, G., Scheetz, T. E. (Ed.). Defensa no Provocativa. Una Propuesta de Reforma Militar para Argentina. Buenos Aires: Editorial Buenos Aires.

Nato. 1994. Partnership for Peace: Framework Document. Meeting of the North Atlantic Council. Disponível em: <http://www.nato.int/cps/en/natolive/official_texts_24469.htm>. Acesso em: 22 Dez. 2016.

Saín, M. F. 2000. Democracia e Forças Armadas - entre a subordinação militar e os 'defeitos' civis. In: D’Araujo, M. C., Castro, C. (Ed.). Democracia e Forças Armadas no Cone Sul. Rio de Janeiro: Ed Fundação Getulio Vargas. 
Saint-Pierre, H. L. 2007. Controle Civil sobre os Militares e Política de Defesa na Argentina, no Brasil, no Chile e no Uruguai. São Paulo: Editora UNESP.

Sedra, M. 2014. Reforma do Setor de Segurança nos Países Afetados por Conflitos: a necessidade de uma abordagem da Segunda Geração. In: Aguilar, S. L. C. (Ed.). Reforma do Setor de Segurança: teoria, prática e crítica. São Paulo: Porto de Idéias.

Snyder, G. H., Diesing, P. 1977. Conflict Among Nations: bargaining, decision-making and System Structure in International Crisis. Princeton: Princeton University Press.

Stepan, A. 1988. Repensando a los militares en política. Cono Sur: un análisis comparado. Buenos Aires: Planeta.

Terpstra, R. 1996. The OSCE Code of Conduct: Setting new standards in the politico-military field? Helsinki Monitor, 7 (1), 27-41.

UN. 2000. $A / 55 / 305-S / 2000 / 809$. Comprehensive Review of the Whole Question of Peacekeeping Operations. New York, 21 Aug. Disponível em: <http://www. un.org/documents/ga/docs/55/a55305.pdf >. Acesso em: 21 jan. 2013.

. 2008. Civil-Military Guidelines \& Reference for Complex Emergencies. New York: Office for the Coordination of Humanitarian Affairs.

DPKO. 2016. Peacekeeping Fact Sheet. New York, 31 December 2016. Disponível em: <http://www.un.org/en/peacekeeping/resources/statistics/ factsheet. shtml\#MONUSC >. Acesso em: 05 fev. 2017.

DPKO/DFS. 2010. Civil-Military Coordination in UN Integrated Peacekeeping Missions (UN-CIMIC). New York: Office of Military Affairs, Policy and Doctrine.A persistente primazia política da corporação militar 


\section{NOTAS}

1. Ver, por exemplo, Feaver 1998; López 1995; López 2007; Stepan 1988; Saín 2000; Saint-Pierre 2007.

2. Na década de 1990, a União Europeia, a Organização para a Segurança e Cooperação na Europa (OSCE) e a Organização do Tratado do Atlântico Norte (OTAN), dentre outras, desenvolveram uma série de ações para o estabelecimento de novas e democráticas relações civis-militares. Diversos programas relacionados com o processo de ampliação da UE com o 'Phare' (Polonia e Hungria) e 'Tacis' (países da Comunidade de Estados Independentes e Georgia) e o SAP - Stabilisation and Association Process (Balcãs) incluíram o desenvolvimento dessas relações, assim como o Código de Conduta de Relações Político-Militares lançado pela OSCE (1994) e o programa Parceria para a Paz (1994) da OTAN direcionado para países da Europa central e do leste (Terpstra 1996; NATO 1994; Cremona 2003; EU 1999; EU 1989).

3. As operações passaram a ser consideradas multidimensionais por abrangerem dimensões diversas como política, desenvolvimento, ajuda humanitária, estado de direito, aspectos sociais, segurança, infraestrutura, eleições, etc). Para atingir as diferentes dimensões das operações fou necessário adotar uma abordagem integrada.

4. A UNTAET foi a Administração Transitória das Nações Unidas em Timor Leste (1999-2002), substituída pela UNMISET - Missão das Nações Unidas de Apoio a Timor-Leste (2002-2005).

5. Ver, por exemplo Allison 1971 e Snyder; Diesing 1977.

6. Parte dessas instituições passaram para o BRABAT 2 que foi desdobrado no Haiti após o terremoto (BRABAT 2010).

7. Informação prestada ao autor pelo Chefe da Seção de Assuntos Civis (G9) do BRABAT em Porto Príncipe, Haiti, em 23 de outubro de 2011. 


\section{A COORDENAÇÃO CIVIL-MILITAR NAS OPERAÇÕES DE PAZ E O BRASIL: ALGUMAS CONSIDERAÇÕES}

\section{RESUMO}

$\mathrm{O}$ texto parte das relações civis-militares de maneira mais ampla para apresentar algumas considerações sobre o tema nas operações de paz. No final, apresenta considerações sobre algumas características dos militares brasileiros e do emprego das forças armadas no país que contribuem para as relações civis-militares nas missões de paz.

Palavras-chave: Operações de Paz; CIMIC; Brasil, ONU.

\section{ABSTRACT}

The text starts from civil-military relations in broadly sense to present some considerations on the subject in peace operations. In the end, it presents considerations about some characteristics of the Brazilian military and the employment of the armed forces within the country which contribute to the civil-military relations in these operations.

Keywords: Peace Operations; CIMIC; Brazil, UN. 